\title{
Rendahnya Praktik Menyusui pada Ibu Post Sectio Caesarea dan Dukungan Tenaga Kesehatan di Rumah Sakit
}

\section{The Low Practices of Breastfeeding for Sectio Caesarea Women and Health Workers Support in Hospital}

\author{
Dwi Retno Wulandari, Linda Dewanti
}

\author{
Departemen Ilmu Kesehatan Masyarakat Kedokteran Pencegahan Fakultas Kedokteran Universitas Airlangga
}

\begin{abstract}
Abstrak
Penelitian terdahulu menyebutkan bahwa ibu melahirkan secara sectio caesarea cenderung lebih lambat melakukan inisiasi menyusu dini dan mempunyai prevalensi lebih rendah dalam praktik ASI ekslusif dibanding Ibu melahirkan pervaginam. Ibu post sectio caesarea juga tidak memulai menyusui bayinya pada hari pertama melahirkan. Tujuan penelitian ini adalah mengetahui faktor yang menyebabkan rendahnya praktik inisiasi ASI pada lbu post sectio caesarea termasuk peran tenaga kesehatan di sebuah rumah sakit di Surabaya. Sebanyak 72 ibu yang melahirkan secara sectio caesarea selama bulan Juni 2012 telah menandatangani informed consent, diobservasi sejak masuk rumah sakit sampai akhir hari ke-2 post sectio caesarea, dan diwawancara dengan menggunakan kuesioner. Hasil penelitian menunjukkan semua ibu sudah mempunyai pengetahuan yang baik tentang ASI, $26,4 \%$ di antaranya sudah mempunyai pengalaman sebelumnya dalam memberikan ASI, tetapi hanya $6,9 \%$ dan total $29,2 \%$ yang mulai memberikan ASI pada hari pertama dan kedua pasca sectio caesarea. Dukungan tenaga kesehatan dalam hal membantu proses pemberian ASI dilaporkan masih rendah. Uji korelasi mendapatkan bahwa dukungan tenaga kesehatan dan kondisi rawat gabung adalah faktor yang berhubungan dengan praktik pemberian ASI ( $p$ value 0,39; $p=0,001$; phi value $=0,47 ; p=0,001)$. Rendahnya pemberian ASI ibu pasca sectio caesarea berkorelasi dengan rendahnya dukungan tenaga kesehatan dan penundaan rawat gabung.
\end{abstract}

Kata kunci: Dukungan tenaga kesehatan, praktik menyusui, sectio caesarea

\section{Abstract}

Previous studies showed that breastfeeding initiation was late in babies born with sectio caesarea compared to those with vaginal delivery and prevalence of exclusive breastfeeding practice was low in the former group. There was no breastfeeding initiation in the first day of post sectio caesarea. The objective of this study was to define factors correlated to low breast- feeding practice initiation on post sectio caesarea mother, including the role of health workers in a hospital in Surabaya. 72 post sectio caesarea mothers were observed and interviewed on 1-30 June 2012 to find the factors correlated with breastfeeding practice. The results showed that although all the mothers already had a good knowledge about breastfeeding, and $26.4 \%$ of them had previous experience in breastfeeding, only $6.9 \%$ and $29.2 \%$ of total breastfeeding is started on the first and second post sectio caesarea respectively. Support for breastfeeding practice from health workers was low, and there were significant correlation between the support and rooming conditions with breastfeeding practices $(p=0.001)$. We concluded that low level of breastfeeding practice on mother with sectio caesarea correlated with low support of health professional and with the delay of room-in practice.

Keywords: Health professional support, breastfeeding practice, sectio caesarea

\section{Pendahuluan}

Air susu ibu (ASI) merupakan makanan terbaik dan tidak tergantikan oleh apapun untuk tumbuh kembang bayi, menunjang kesehatan bayi secara optimal, serta mewujudkan ikatan emosional antara ibu dan bayinya. ${ }^{1,2}$ Target ASI eksklusif Indonesia Sehat 2010 adalah $80 \% .^{3}$ Prevalensi sectio caesarea terus meningkat dari tahun ke tahun, terutama di kota besar. Menurut data Survei Demografi dan Kesehatan Indonesia tahun 2007, sectio caesarea menyumbang penurunan angka kematian ibu (AKI) sebesar $25 \%$, tetapi hal tersebut perlu diwaspadai karena bayi yang lahir melalui sectio caesarea mempun-

Alamat korespondensi: Linda Dewanti, Departemen IKM-KP Fakultas Kedokteran Universitas Airlangga, Jl. Mayjend Prof. Dr. Moestopo 47 Surabaya 60132,Hp.081231670967,e-mail: lindaperisdiono@yahoo.com 
yai risiko lebih tinggi untuk tidak disusui oleh ibunya dibandingkan persalinan pervaginam. ${ }^{4,5} \mathrm{Hal}$ ini dapat disebabkan beberapa hal misalnya, kondisi post sectio caesarea membuat ibu merasa nyeri dan menjadi sulit untuk menyusui bayinya, keterlambatan untuk melakukan inisiasi menyusui dini dapat menurunkan sekresi prolaktin. ${ }^{6,7}$ Tinjauan sistematis yang melibatkan 33 negara mendapatkan hasil bahwa prevalensi menyusui dini lebih rendah pada ibu post sectio caesarea dibandingkan dengan yang melahirkan pervaginam. ${ }^{8}$ Data studi terdahulu juga menemukan bahwa, 100\% ibu post sectio caesarea tidak memulai menyusui bayinya pada hari pertama melahirkan.

Tanpa membedakan jenis persalinan, pervaginam atau sectio caesarea, secara umum pemberian ASI dipengaruhi beberapa faktor, antara lain dukungan tenaga kesehatan, keadaan ibu (fisik dan psikologis), perubahan sosial budaya, tata laksana di rumah sakit, kesehatan bayi, pengetahuan ibu, sikap ibu, lingkungan keluarga, peraturan pemasaran pengganti ASI, dan paritas. ${ }^{5,9,10}$ Ditengarai bahwa 24 jam setelah ibu melahirkan adalah saat yang sangat penting untuk inisiasi pemberian ASI dan akan menentukan keberhasilan menyusui selanjutnya. ${ }^{2}$ Jika ibu tidak mulai memberikan ASI lebih dari dua hari setelah postpartum, respons pengeluaran prolaktin akan sangat menurun. ${ }^{11}$ Situasi ini terjadi pada persalinan dengan sectio caesarea. Pemberian ASI oleh ibu yang telah menjalani sectio caesarea sebenarnya dapat langsung dilakukan karena operasi dilakukan dengan anestesi spinal atau epidural sehingga ibu tetap sadar. Posisi menyusui dapat disesuaikan dengan kondisi ibu, misalnya dengan posisi berbaring (lying down), posisi duduk, dan football hold sehingga hal ini sebenarnya tidak menjadi penghalang bagi praktik pemberian ASI. ${ }^{2}$

Mengingat semakin banyaknya ibu melahirkan dengan sectio caesarea, pentingnya menyusui dini demi kesuksesan keberlangsungan pemberian ASI kepada bayi, serta pentingnya peran petugas kesehatan dalam mendukung pemberian ASI terutama pada hari-hari pertama melahirkan, maka penelitian ini ingin mempelajari rendahnya praktik pemberian ASI pada ibu melahirkan dengan sectio caesarea dan hubungannya dengan dukungan petugas kesehatan. Pengetahuan, sikap ibu, status paritas, dan karakteristik ibu dengan praktik menyusui juga dianalisis.

\section{Metode}

Penelitian ini adalah penelitian analitis dengan desain potong lintang. Semua ibu melahirkan dengan sectio caesarea yang masuk dalam kriteria inklusi pada periode 1 - 30 Juni 2012 di sebuah rumah sakit kawasan Surabaya Timur diminta menjadi responden setelah mereka menandatangani informed consent. Kriteria inklusi adalah ibu tidak mempunyai penyakit lain (jantung, kanker, pre-eklampsia/eklampsia, luka herpes pada payudara), ibu dengan bayi yang normal, bayi dapat minum per-oral, bayi yang tidak menerima cairan melalui infus, bayi yang menderita galaktosemia. Jika setelah sectio caesarea ibu memerlukan terapi khusus, kondisi tidak stabil, perdarahan, gangguan kesadaran, kondisi bayinya tidak normal dan atau memerlukan terapi khusus, maka ibu tersebut dikeluarkan sebagai responden. Total terdapat 72 responden yang bersedia berpartisipasi dalam penelitian ini yang memenuhi kriteria.

Umur, tingkat pendidikan, jenis pekerjaan, status paritas, pengalaman menyusui, pengetahuan dan sikap ibu tentang menyusui serta dukungan petugas kesehatan di ruang nifas didapatkan dengan wawancara menggunakan kuesioner dan observasi secara langsung menggunakan lembar observasi (check-list). Wawancara dan observasi dilakukan pada hari pertama dan akhir hari kedua setelah ibu melahirkan saat ibu sudah cukup beristirahat dan dalam kondisi yang nyaman. Jika masih ada tindakan medis yang harus dilakukan, misalnya ibu masih merasa nyeri, lelah, lemah, dan mengantuk, wawancara dan observasi akan dilakukan setelah kondisi ibu siap.

\section{Hasil}

Semua responden mengaku sudah pernah mendapatkan informasi tentang pentingnya pemberian ASI dari berbagai sumber antara lain teman, keluarga, petugas kesehatan, media cetak dan media elektronik (Tabel 1). Mayoritas $(80,6 \%)$ skor pengetahuan mereka tentang ASI menunjukkan hasil yang baik dan cukup baik (Tabel 2).

Dari hasil wawancara, lebih dari separuh ibu $(58,3 \%)$ menyatakan kurang setuju dengan pemberian ASI pada hari pertama sectio caesarea. Hasil observasi menunjukkan bahwa meskipun 19 ibu (26,4\%) sudah mengeluarkan ASI pada hari pertama post sectio caesarea tetapi hanya $5 \mathrm{ibu}(6,9 \%)$ yang memberikan ASI kepada

Tabel 1. Karakteristik Responden

\begin{tabular}{llll}
\hline Variabel & Kategori & n & $\%$ \\
\hline Pendidikan & Tidak sekolah & 1 & 1,4 \\
& Pendidikan dasar & 29 & 40,3 \\
& Pendidikan menengah & 38 & 52,8 \\
& Pendidikan tinggi & 4 & 5,6 \\
Usia & Mean/SD* & 31 & 6,7 \\
Pekerjaan & Bekerja & 21 & 29,2 \\
Paritas & Tidak bekerja & 51 & 70,8 \\
& Primipara & 21 & 29,2 \\
Pengalaman menyusui & Multipara & 51 & 70,8 \\
& Pernah & 48 & 66,7 \\
Informasi tentang ASI sebelumnya & Belum pernah & 24 & 33,3 \\
& Pernah & 72 & 100 \\
Sumber informasi tentang ASI & Tidak pernah & 0 & 0 \\
& Petugas kesehatan & 45 & 62,5 \\
& Media elektronik & 21 & 29,2 \\
& Media cetak & 22 & 30,6 \\
& Teman/keluarga & 52 & 72,2 \\
\hline
\end{tabular}


bayinya pada hari tersebut. Sebanyak 72 ibu melahirkan dengan cara sectio caesarea, 54 orang $(75 \%)$ belum berada satu ruang dengan bayinya (rawat gabung) pada hari pertama. Petugas tenaga kesehatan akan memberikan bayi kepada ibunya untuk disusui jika si ibu sudah kentut dan kateter urin serta infus sudah dilepas.

Dukungan tenaga kesehatan dalam praktik inisiasi dini ASI dinilai baik oleh sebagian kecil responden $(12,5 \%)$, cukup $(20,8 \%)$, dan dinilai kurang oleh mayoritas responden $(66,7 \%)$. Ketika ditanya alasan tidak

Tabel 2. Pengetahuan, Sikap, Praktik Pemberian ASI Ibu PostSectio Caesarea dan Dukungan Tenaga Kesehatan $(n=72)$

\begin{tabular}{llll}
\hline Variabel & Kategori & n & $\%$ \\
\hline Pengetahuan ASI & Baik & 27 & 37,5 \\
& Cukup & 31 & 43,1 \\
Sikap pemberian ASI post sectio caesarea & Kurang & 14 & 19,4 \\
& Positif & 30 & 41,7 \\
Produksi ASI hari pertama & Negatif & 42 & 58,3 \\
& Sudah keluar & 19 & 26,4 \\
Rawat gabung hari pertama & Belum keluar & 53 & 73,6 \\
& Sudah & 18 & 25 \\
Praktik pemberian ASI post sectio caesarea & Belum & 54 & 75 \\
hari pertama & Ya & 5 & 6,9 \\
Dukungan tenaga kesehatan & Tidak & 67 & 93,1 \\
& Baik & 9 & 12,5 \\
& Cukup & 15 & 20,8 \\
& Kurang & 48 & 66,7 \\
\hline
\end{tabular}

Tabel 3. Alasan Responden Tidak Memberikan ASI pada Post Sectio Caesarea Hari Pertama $(n=67)$

\begin{tabular}{lll}
\hline Alasan Responden & n & $\%$ \\
\hline Belum rawat gabung & 54 & 75 \\
Ibu belum bisa duduk & 53 & 73,6 \\
ASI belum keluar & 53 & 73,6 \\
Nyeri luka operasi & 14 & 19,4 \\
Puting susu datar & 2 & 2,8 \\
Suami melarang menyusui & 1 & 1,4 \\
Bayi akan diadopsi & 1 & 1,4 \\
\hline
\end{tabular}

Keterangan: Responden boleh memberikan lebih dari satu alasan melakukan inisiasi untuk memberikan ASI pada hari pertama post sectio caesarea, jawaban terbanyak adalah karena ibu belum rawat gabung dengan bayinya (75\%), ibu belum bisa duduk $(73,5 \%)$, dan ASI belum keluar $(73,5 \%)$ (Tabel 3). Dari 19 ibu yang sudah memproduksi ASI pada hari pertama melahirkan post sectio caesarea, hanya $5 \mathrm{ibu}(26,3 \%)$ yang memberikan ASI kepada bayi (praktik menyusui), sementara $73,7 \%$ ibu tidak memberikan ASI yang sudah keluar kepada bayinya.

Tidak ada perbedaan usia ibu yang menyusui bayinya pada hari pertama postpartum dengan ibu yang tidak menyusui bayinya. Status paritas, pengetahuan dan sikap ibu tentang pentingnya pemberian ASI juga tidak ada hubungannya dengan praktik pemberian ASI hari pertama sectio caesarea. Pada Tabel 4 terlihat bahwa dukungan tenaga kesehatan dan rawat gabung pada hari pertama ada hubungannya dengan praktik pemberian ASI pada hari pertama sectio caesarea $(\mathrm{p}=0,001$ dan $\mathrm{p}=$ $0,001)$.

\section{Pembahasan}

Penelitian ini menunjukkan bahwa dukungan tenaga kesehatan bagi ibu melahirkan secara sectio caesarea untuk melakukan inisiasi dini dan praktik rawat gabung (ibu dan bayi dalam satu ruangan) ada hubungannya dengan tindakan ibu untuk menyusui bayi secara dini (nilai $\mathrm{p}=0,39 ; \mathrm{p}=0,001$; nilai $\mathrm{p}=0,47 ; \mathrm{p}=0,001$ ), sedangkan pengetahuan dan sikap tentang pemberian ASI, status paritas serta riwayat menyusui pada kelahiran sebelumnya tidak ada hubungannya dengan tindakan ibu untuk menyusui secara dini (nilai $p>0,05$ ).

Kondisi ibu pasca sectio caesarea sangat memerlukan dukungan dari tenaga kesehatan dengan menunjukkan bayi kepada ibu dan memberikan bayi untuk disusui. Hal ini terbukti sangat membuat kondisi ibu nyaman dan puas. ${ }^{13}$ Intervensi "early skin to skin" pasca sectio cae-

Tabel 4. Hubungan Rawat Gabung dan Dukungan Tenaga Keseharan dengan Pemberian ASI PostSectio Caesarea Hari Pertama

\begin{tabular}{|c|c|c|c|c|c|c|c|}
\hline \multirow{3}{*}{ Variabel } & \multirow{3}{*}{ Kategori } & \multicolumn{4}{|c|}{$\begin{array}{c}\text { Praktik Pemberian ASI Hari Pertama } \\
\text { Post Sectio Caesarea }\end{array}$} & \multirow{3}{*}{$\begin{array}{l}\text { Fisher's Exact } \\
\text { Test }(\mathrm{p})\end{array}$} & \multirow{3}{*}{ Nilai p } \\
\hline & & \multicolumn{2}{|c|}{ Ya } & \multicolumn{2}{|c|}{ Tidak } & & \\
\hline & & $\mathbf{n}$ & $\%$ & $\mathbf{n}$ & $\%$ & & \\
\hline \multirow[t]{2}{*}{ Pengalaman menyusui } & Ya & 5 & 100 & 43 & 64,2 & $0,162 \S$ & - \\
\hline & Tidak & 0 & 0 & 24 & 35,8 & & \\
\hline \multirow{2}{*}{ Paritas } & Primipara & 0 & 0 & 21 & 31,3 & 0,31 & - \\
\hline & Non primipara & 5 & 100 & 46 & 68,7 & & \\
\hline \multirow[t]{2}{*}{ Pengetahuan Ibu } & Baik dan cukup & 5 & 100 & 49 & 73,1 & 0,32 & - \\
\hline & Kurang & 0 & 0 & 18 & 26,9 & & \\
\hline \multirow[t]{2}{*}{ Sikap } & Positif & 4 & 80 & 26 & 38,8 & $0,15 \S$ & - \\
\hline & Negatif & 1 & 20 & 41 & 61,2 & & \\
\hline \multirow[t]{2}{*}{ Rawat gabung hari pertama } & $\mathrm{Ya}$ & 5 & 100 & 13 & 19,4 & 0,001 & $0,47(0,001)$ \\
\hline & Tidak & 0 & 0 & 54 & 80,6 & & \\
\hline \multirow[t]{2}{*}{ Dukungan tenaga kesehatan } & Baik dan cukup & 5 & 100 & 19 & 28,4 & 0,003 & $0,39(0,001)$ \\
\hline & Kurang & 0 & 0 & 48 & 71,6 & & \\
\hline
\end{tabular}


sarea di Rumah Sakit General Hospital San Francisco terbukti meningkatkan praktik menyusui dan dinyatakan bahwa peranan perawat adalah kunci keberhasilan program intervensi tersebut. ${ }^{14}$ Pentingnya dukungan tenaga kesehatan terhadap praktik menyusui juga ditunjukkan oleh Labarere dkk, ${ }^{12}$ yang menyatakan bahwa kunjungan tenaga kesehatan bulan kesatu hingga keenam pada ibu melahirkan setelah keluar rumah sakit ada hubungannya dengan prosentasi ibu memberikan ASI ekslusif dan dengan durasi menyusui.

Dari penelitian ini, terungkap bahwa praktik pemberian ASI hanya dilakukan oleh 6,9\% responden pada hari tersebut walaupun sebenarnya $26,4 \%$ dari seluruh responden sudah memproduksi ASI sejak hari pertama post sectio caesarea. Total sampai dengan akhir hari kedua post sectio caesarea, 29,2\% dari responden mulai menyusui bayinya. Kondisi ini serupa dengan studi yang meliputi 33 negara yang menyatakan bahwa inisiasi pemberian ASI lebih rendah pada Ibu yang melahirkan dengan sectio caesarea dibanding ibu yang melahirkan per vaginam. ${ }^{15}$ Ibu post sectio caesarea berisiko tiga kali lebih besar untuk terlambat melakukan inisiasi menyusui dibanding dengan melahirkan pervaginam dan pemberian ASI ekslusif pada ibu melahirkan dengan sectio caesarea kepada bayinya juga didapatkan $16 \%$ lebih rendah dibandingkan dengan ibu melahirkan per vaginam. 5,7,8

Tidak ada hubungan antara umur ibu, status paritas, pengetahuan, dan sikap ibu tentang pentingnya pemberian ASI dengan praktik menyusui dini pada hari pertama post sectio caesarea. Penelitian di Hongkong menunjukkan bahwa suami sangat berperan pada praktik inisiasi ibu untuk menyusui bayinya sedangkan tingkat pendidikan ibu yang tinggi dan status ibu bekerja berhubungan dengan dihentikannya pemberian ASI oleh ibu yang diganti dengan pemberian susu formula. ${ }^{16}$

Notoatmodjo, ${ }^{17}$ menyatakan bahwa sikap terhadap nilai-nilai kesehatan tidak selalu terwujud dalam suatu tindakan nyata. Ibu yang telah menjalani operasi lebih memilih untuk pasif dan beristirahat daripada segera memberikan ASI pada bayinya walaupun ibu tahu bahwa ASI merupakan makanan terbaik bagi bayi. Selain itu, tenaga kesehatan setempat juga tidak menganjurkan dan mendukung ibu untuk sesegera mungkin memberikan ASI, yang mengakibatkan penundaan inisiasi menyusui bayi secara dini. Keterlambatan tersebut dapat menurunkan sekresi prolaktin, zat esensial untuk memproduksi dan menjaga kestabilan produksi ASI yang selanjutnya akan memengaruhi kecukupan ASI ekslusif bagi bayi. ${ }^{18}$

\section{Kesimpulan}

Rendahnya praktik pemberian ASI oleh ibu post sectio caesarea kepada bayinya ada hubungannya dengan dukungan tenaga kesehatan dan praktik rawat gabung.

\section{Saran}

Rumah sakit perlu meningkatkan kebijakan yang mendukung inisiasi menyusui dini khususnya bagi ibu melahirkan dengan sectio caesarea dan tenaga kesehatan perlu secara aktif memberikan dukungan pada ibu post sectio caesarea untuk segera melakukan inisiasi pemberian ASI bagi bayinya.

\section{Daftar Pustaka}

1. Direktorat Bina Pelayanan Keperawatan dan Keteknisian Medik Kementrian Kesehatan Republik Indonesia. Keputusan menteri Kesehatan RI No.230/ MENKES/ SK/ II/ 2010 tentang pedoman rawat gabung ibu dan bayi. Jakarta: Kementrian Kesehatan Republik Indonesia; 2010.

2. Ikatan Dokter Anak Indonesia (IDAI). Indonesia menyusui. Jakarta: Badan Penerbit IDAI; 2010.

3. Dinas Kesehatan Jawa Timur. Profil kesehatan Provinsi Jawa Timur [online]. 2010 [diakses tanggal 15 Maret 2013]. Diunduh dalam: h t t p : / / inkes.jatimprov.go.id/userfile/dokumen/ 1321926974_Profil_Kesehatan_Provinsi_Jawa_Timur_2010.pdf. 2010.

4. Bodner K, Wierrani F, Grünberger W, Bodner-Adler B. Influence of the mode of delivery on maternal and neonatal outcomes: a comparison between elective cesarean section and planned vaginal delivery in a lowrisk obstetric population. Archives of Gynecology Obstetrics. 2011; 283 (6): 1193-8.

5. Senarath U, Siriwardena I, Godakandage SS, Jayawickrama H, Fernando DN, Dibley MJ. Determinants of breastfeeding practices: an analysis of the Sri Lanka Demographic and Health Survey 2006-2007. Maternal and Child Nutrition. 2012; 8 (3): 315-29.

6. Karlstrom A, Engstrom-Olofsson R, Norbergh KG, Sjoling M, Hildingsson I. Postoperative pain after cesarean birth affects breastfeeding and infant care. Journal of Obstetric, Gynecologic, and Neonatal Nursing. 2007; 36 (5): 430-40.

7. Awi DD, Alikor EA. Barriers to timely initiation of breastfeeding among mothers of healthy full-term babies who deliver at the University of Port Harcourt Teaching Hospital. Nigerian Journal of Clinical Practice. 2006; 9 (1): 57-64.

8. Prior E, Santhakumaran S, Gale C, Philipps LH, Modi N, Hyde MJ. Breastfeeding after cesarean delivery: a systematic review and meta analysis of world analysis. American Journal of Clinical Nutrition. 2012; 95 (5):1113-35.

9. Departemen Kesehatan Republik Indonesia. Manajemen laktasi: buku panduan bagi bidan dan petugas kesehatan di puskesmas. Jakarta: Direktorat Gizi Masyarakat Departemen Kesehatan Republik Indonesia.; 2005.

10. Laantera S, Polkki T, Ekstrom A, Pietilä AM. Breastfeeding attitudes of Finnish parents during pregnancy. BMC Pregnancy Childhbirth. 2010; 10: 79 .

11. Manuaba IBG, Manuaba IAC, Manuaba IBGF. Pengantar kuliah obstetri. Jakarta: EGC; 2007.

12. Labarere J, Gelbert-Baudino N, Ayral AS, Duc C, Berchotteau M, Bouchon N, et al. Efficacy of breastfeeding support provided by trained clinicians during an early, routine, preventive visit: a prospective, randomized, open trial of 226 mother-infant pairs. Pediatrics. 2005 Feb; 
115 (2): e139-46.

13. Kumar VRH, Jahagirdar SM, Athiraman UK, Sripriya R, Parthasarathy S, Ravishankar M. Study of patient satisfaction and self-expressed problems after emergency caesarean delivery under subarachnoid block. Indian Journal of Anaesthesia. 2014 Mar-Apr; 58( 2): 149-53.

14. Hung KJ, Berg O. Early skin-to-skin after cesarean to improve breastfeeding. MCN: The American Journal of Maternal/Child Nursing. 2011 Sep-Oct; 36 (5): 318-24.

15. Alves AL, Oliveira MI, Moraes JR. Breastfeeding-friendly primary care unit initiative and the relationship with exclusive breastfeeding. Revista de Saude Publica. 2013 Dec; 47 (6): 1130-40.

16. Lee WT, Wong E, Lui SS, Chan V, Lau J. Decision to breastfeed and early cessation of breastfeeding in infants below 6 months old-a population-based study of 3,204 infants in Hong Kong. Asia Pacific Journal of Clinical Nutrition. 2007;16 (1): 163-71.

17. Notoatmodjo S. Promosi kesehatan dan ilmu perilaku. Jakarta: PT. Rineka Cipta; 2007.

18. Riordan J, Wambach K. Breastfeeding and human lactation. $4^{\text {th }}$ ed. Sudbury: Jones \& Barlett Publisher; 2010. 